\title{
The Application of Integrated Geophysical Exploration Methods in Daqinggou Molybdenum Deposit
}

\author{
Xiang Yu, Zhaohua Luo, Jinhua Cheng \\ School of the earth science and Resources, \\ China University of Geosciences, \\ Beijing, 10029.China
}

\author{
Cong Chen, Dan Ke, Xiang Yu \\ Beijing Research Institute of Uranium Geology, \\ Beijing, 10083.China
}

\begin{abstract}
Daqinggou molybdenum deposit locates in daqinggou miaozi area luanchuan county, Henan province. It is considered to be a favorable metallogenic area because of the intense tectonic movement and frequent magmatic activities. This molybdenum deposit is a medium-sized deposit and the ore bodies are strictly controlled by stratum, lithology, structures and environment of ancient geography as well as magmatic rocks. The author 1.compares the difference of physical properties in the first place, then divides research area into two abnormal areas (North and South); 2.identifies four density layers and three interfaces in the vertical direction with bouguer gravity anomaly, G5 low density anomaly, G6 low density anomaly and G9 low density anomaly between Caledonian Iron rich ekerite and the location of north Taihua group; 3.Analyzes the IP sounding result which infers that TA-2 anomaly is the similar one to the TA-1 anomaly and it's also as a favorable molybdenum mineralization location in the Luocun molybdenum deposit. In conclusion, according to some geological data and geophysical information, this research plays an important role in selecting prospecting target area in hidden porphyry type polymetallic molybdenum deposit.
\end{abstract}

Keywords-integrated Geophysical Exploration Methods; IP anomalies; bouguer gravity anomaly

\section{INTRODUCTION}

Daqinggou molybdenum deposit where locate in daqinggou luanchuan county, henan province [1]. In this research area, it has been undertook some geological and geophysical work such as regional geological survey (1:200 $000)$, aeromagnetic survey (1:50 000). There has been found several CulPb\Zn mineralized belts surrounds by molybdenum ore body which highly enrich in nonferrous metals. Daqinggou deposit locate in the north of luanchuan polymetallic belt which belongs to subzone of east part qingling molybdenum mineralization belt[2].The author summarizes symbols of gravitational and induced polarization prospecting in research area and provides significant evidence for locating the optimized target area of dongqingling-dabieshan hidden porphyry molybdenum deposit belts.

\section{REgIONAL GEOLOGICAL SURVEY}

Daqinggou molybdenum deposit is located in the north part of lushi-luanchuan polymetallic belts. There exposes large scales of Archean taihua group gneiss, migmatite in research area. Mesoproterozoic xiong'er xushan group andesite which crop out in northwest fault and igneous rocks distributes extensively in the southern part of surveying area such as Caledonian Dragon King group granite which rich in $\mathrm{Fe}, \mathrm{Na}$; metagabbro veins; yanshan period luocun granite-porphyry[3] (Figure 1) .There is a correlate relationship between the formation of molybdenum deposit and the invasion of granite-porphyry body, porphyry body which rich in molybdenum hides in the contact zone of Dragon King granite and taihua group stratum. The characters of zonation separate into high, mesothermal and low temperature districts [4].

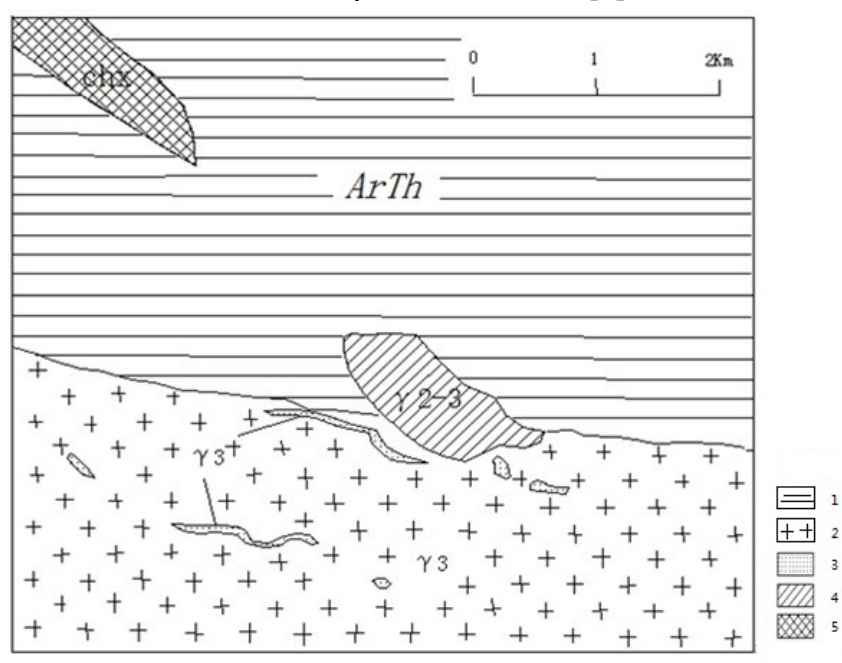

Figure 1. Geological sketch map in research area

1-Taihua group migmatite 2- Dragon King Group granite 3- gabbro veins

4-Luocun granite-porphyry 5- Changchengian System Xiong'er Group andesite

\section{GEOPHYSICAL SURVEY}

\section{A. Gravity surveys}

Full range of gravity data $(1: 10000)$ covers the molybdenum polymetallic mining area. The stratum and rock density parameters of this main area are as follows (Table I) 
TABLE I. STRATUM (ROCK) DENSITY PARAMETERS

\begin{tabular}{cc}
\hline stratum(rock) & Density $\left(\mathrm{g} / \mathrm{cm}^{3}\right)$ \\
Taihua group & 2.68 \\
(gneiss,amphibole & \\
plagiogneiss) & 2.58 \\
The Xionger group, Xu \\
$\begin{array}{c}\text { Shan Group (andesite) } \\
\text { The Caledonian Dragon } \\
\text { King group (ganite) } \\
\text { Luocun Yanshanian(grained } \\
\text { granite porphyry) }\end{array}$
\end{tabular}

The Bouguer gravity anomaly in daqinggou molybdenum deposit shows abnormal high in the north while low in the south (Figure 2). The boundary line which is yangpo-wangyuan-beizhuang-wangchanggou, separates abnormal areas into south and north parts. The northern anomaly mainly with high value belts and the gravity field increases from south to north, which also exists several NE trend minima abnormal. There is an obvious geologic structure contrast in our research area which reflects in the south and north abnormal zones. According to the geological data, the north part which shows highly in density is Taihua Group. On the contrary, south part is Caledonian Dragon King Group.

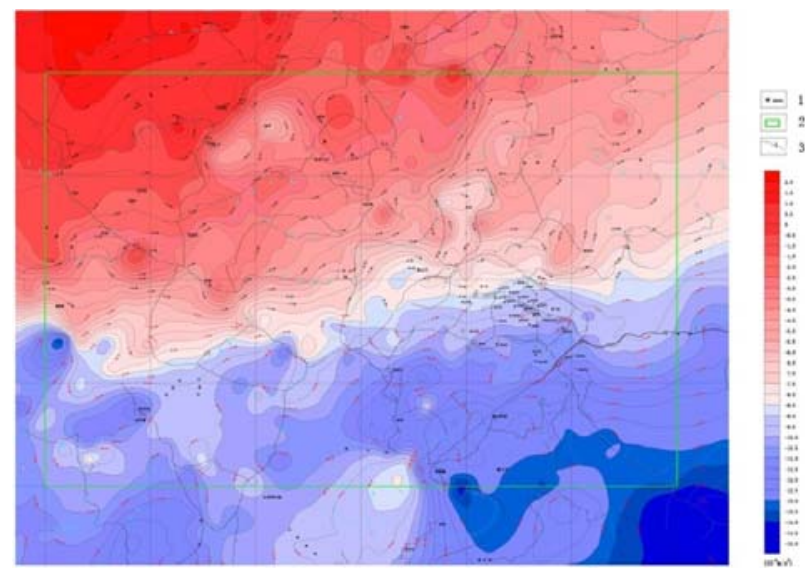

Figure 2. The Bouguer gravity anomaly map 1-boreholes 2-research area 3- Bouguer anomaly isopleths

There are different levels of reflection both in Bouguer gravity anomaly maps and some maps after data processing work. In that case, it should calculate not only residual gravity anomaly but also horizontal level one and two derivative Bouguer gravity anomaly which reflect at different upward continuation height $(0.1 \mathrm{~km} 、 0.3 \mathrm{~km}$ 、 $0.5 \mathrm{~km} 、 1 \mathrm{~km} 、 3 \mathrm{~km} 、 5 \mathrm{~km} 、 7 \mathrm{~km} 、 10 \mathrm{~km})$. Based on the data of Bouguer gravity anomaly and processed data, it easily found that several factors in delineate fracture structures: 1 . the boundary of different gravity field; 2 . Linear gradient belt in Bouguer gravity anomaly; 3.Linear extreme zone in horizontal derivative; 4.The contour of gravity anomaly along the strike distort regularly. Based on these factors above, the gravity field in research area is analyzed.

The Caledonian Dragon King Group intrusive rock and Yanshanian period small intrusive rocks are low density bodies and distributes extensively. According to the determination of petrophysical data, the density of Caledonian Dragon King group intrusive rocks is $2.63 \mathrm{~g} / \mathrm{cm}^{3}$ (average value) while the other one is $2.51 \mathrm{~g} / \mathrm{cm}^{3}$ (average value).The density of most common Taihua group stratum is $2.68 \mathrm{~g} / \mathrm{cm}^{3}$ which is higher than the two types of intrusive rock above and it manifest that two major rocks often display low gravity anomaly. It is effective to delineate acidic granite by analyzing residual gravity anomaly. In order to suppress deep regional geological factors, we uses second derivative in vertical direction to highlight the anomaly which causes by shallow rocks and it also works well in separating the anomaly into different depths and caused by different sources.

In general, it is easy for us to identify the boundary of hidden rock mass by analyzing zero contours in the second derivative of gravity. There are obviously ten locations which reflects low gravity anomaly in the second derivative gravity anomaly (in the vertical direction) map. (Figure 3)

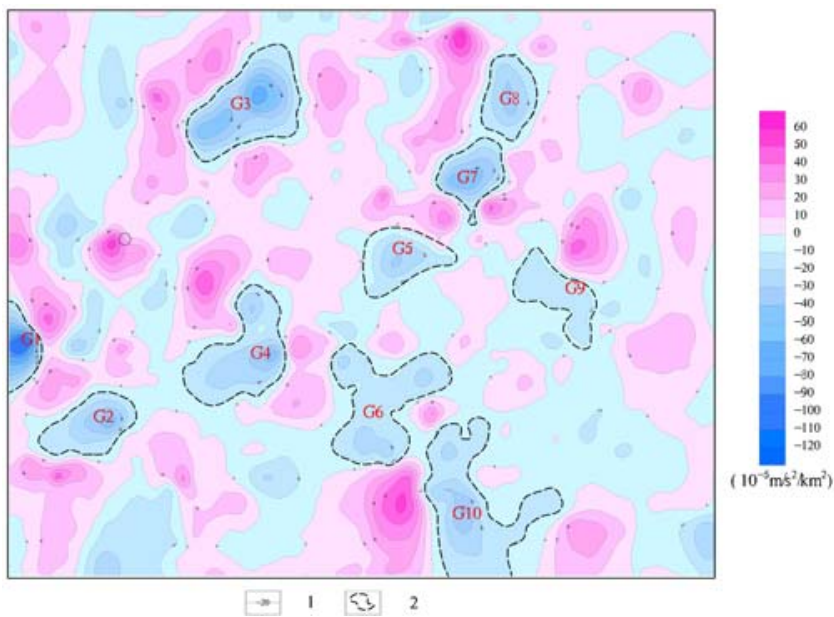

Figure 3. Second derivative gravity anomaly (in the vertical direction) map 1 - isoanomalic contour line 2-anomaly regions

i) South of beidianling low gravity anomaly G1

The G1 anomaly located in the west part of research area, anomaly is a half elliptical and length is about $300 \mathrm{~m}$ long and width is $350 \mathrm{~m}$. The minimum value for the anomaly is $-70 \times 10-5 \mathrm{~m} / \mathrm{s}^{2} / \mathrm{km}^{2}$; we speculate it is caused by thickness Caledonian hastingsite granite stocks.

ii) Nanyeju low gravity anomaly G2

The G2 anomaly located in the south part of research area, anomaly is an elliptical and length is about $850 \mathrm{~m}$ long and width is $450 \mathrm{~m}$. The minimum value for the anomaly is $40 \times 10-5 \mathrm{~m} / \mathrm{s}^{2} / \mathrm{km}^{2}$; we speculate it is caused by thickness Caledonian hastingsite granite stocks.

iii) Gaopin low gravity anomaly G3

The G3 anomaly located in the north part of research area, anomaly is a elliptical and length is about $1000 \mathrm{~m}$ long 
and width is $550 \mathrm{~m}$. There are two minimum values for the anomaly the first one is $-40 \times 10-5 \mathrm{~m} / \mathrm{s}^{2} / \mathrm{km}^{2}$ and the second is $-60 \times 10-5 \mathrm{~m} / \mathrm{s}^{2} / \mathrm{km}^{2}$, we speculate it is caused by Taihua fault depression.

iv) Yangpo low gravity anomaly G4

The G4 anomaly located in the central part of research area and its sharp is Irregular oval, there are two anomalies in this district, one which its north axis towards NS, anomaly length is about $400 \mathrm{~m}$ long and width is $350 \mathrm{~m}$. The minimum value for the anomaly is $-30 \times 10-5 \mathrm{~m} / \mathrm{s}^{2} / \mathrm{km}^{2}$ while the other's south axis towards NE, anomaly length is about $800 \mathrm{~m}$ long and width is $500 \mathrm{~m}$. The minimum value for the anomaly is $-40 \times 10-5 \mathrm{~m} / \mathrm{s}^{2} / \mathrm{km}^{2}$; we speculate it is caused by thickness Caledonian hastingsite granite stocks.

v) Heishijia low gravity anomaly G5

The G2 anomaly located in the middle part of research area, anomaly is a elliptical and length is about $600 \mathrm{~m}$ long and width is $400 \mathrm{~m}$. The minimum value for the anomaly is $30 \times 10-5 \mathrm{~m} / \mathrm{s}^{2} / \mathrm{km}^{2}$; we speculate it is caused by Yanshanian period grained granite porphyry.

vi) Muzhuao low gravity anomaly G6

The G6 anomaly located in the south part of research area , anomaly is separated into 3parts.the first one locates in northwest and length is about $300 \mathrm{~m}$ long and width is $300 \mathrm{~m}$, the minimum value for the anomaly is $-20 \times 10$ $5 \mathrm{~m} / \mathrm{s}^{2} / \mathrm{km}^{2}$; the second one locates in northeast length is about $500 \mathrm{~m}$ long and width is $350 \mathrm{~m}$, the minimum value for the anomaly is $-20 \times 10-5 \mathrm{~m} / \mathrm{s}^{2} / \mathrm{km}^{2}$; the last one locates in south and length is about $600 \mathrm{~m}$ long and width is $400 \mathrm{~m}$, the minimum value for the anomaly is $-20 \times 10-5 \mathrm{~m} / \mathrm{s}^{2} / \mathrm{km}^{2}$. We speculate it is caused by Yanshanian period grained granite porphyry.

vii) Gongpuo low gravity anomaly G7

The G7 anomaly located in the central part of research area, anomaly is an elliptical and length is about $600 \mathrm{~m}$ long and width is $500 \mathrm{~m}$. The minimum value for the anomaly is $50 \times 10-5 \mathrm{~m} / \mathrm{s}^{2} / \mathrm{km}^{2}$; we speculate it is caused by Taihua fault depression.

viii) Aihegou low gravity anomaly G8

The G8 anomaly located in the north part of research area, anomaly is an elliptical and length is about $650 \mathrm{~m}$ long and width is $450 \mathrm{~m}$. The minimum value for the anomaly is $30 \times 10-5 \mathrm{~m} / \mathrm{s}^{2} / \mathrm{km}^{2}$; we speculate it is caused by Taihua fault depression.

ix) Luocun low gravity anomaly G9

The G9 anomaly located in the central part of research area, anomaly is a elliptical and length is about $750 \mathrm{~m}$ long and width is $200 \mathrm{~m}$. The minimum value for the anomaly is $10 \times 10-5 \mathrm{~m} / \mathrm{s}^{2} / \mathrm{km}^{2}$; we speculate it is caused by Yanshanian period grained granite porphyry.

$\mathrm{x})$ Shanyangjuan low gravity anomaly G10

The G10 anomaly located in the south part of research area, anomaly is an elliptical and length is about $1200 \mathrm{~m}$ long and width is $400 \mathrm{~m}$. The minimum value for the anomaly is $-40 \times 10-5 \mathrm{~m} / \mathrm{s}^{2} / \mathrm{km}^{2}$; we speculate it is caused by thickness Caledonian hastingsite granite stocks.

It manifests that Heishijia low gravity anomaly G5, Muzhuao low gravity anomaly G6 and Luocun low gravity anomaly G9 may be caused by Yanshanian period grained granite porphyry which is close relation with mineralization. But the rest of other anomalies aren't related with mineralization.

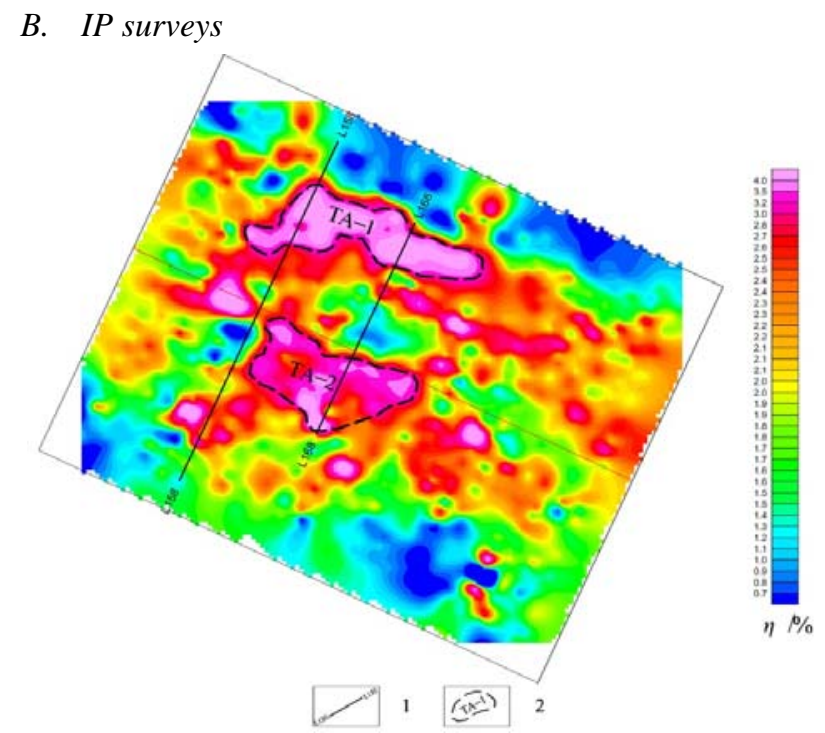

Figure 4 . The apparent polarizability anomaly contour map 1- Symmetric quadrupole sounding profiles 2- Forecasting target area

After gravity surveys, we undertake induced polarization survey. IP survey results which applied in Luocun molybdenum deposit (Figure 4) manifest that there are 2 anomalies in the apparent polarrizability anomaly contour map. It separate into north and south belts; anomaly number is TA-1, TA-2. TA-1 anomaly irregularly distribute in beizhuan and luocun districts, the width of this anomaly is about 220 470m; The length is $1300 \mathrm{~m}$; the pink of anomaly is $5.59 \%$.

Because of IP anomaly region is a known molybdenum location, we could infer that anomalies are highly relate with molybdenum mineralization. TA-2 anomaly parallel with the TA-1which locate in caoping district and the width of this anomaly is about $150 \sim 600 \mathrm{~m}$; The length is $1600 \mathrm{~m}$; the pink of anomaly is $6.57 \%$. Northwest of TA-2 anomaly is connect to the southwest of TA-1 anomaly, and the sharp or scale is similar to TA-1 anomaly. IP anomaly is a known molybdenum location and controlled by 3 drilling holes, we could figure out that TA-2 anomaly follows a similar pattern which caused by luocun rock body and metamorphic rocks in contact zone. In conclusion, the location of TA-2 anomaly is a mineralization favorable position.

\section{CONCLUSION}

This paper combines the structure of geological data, property data and some geophysical results to find out mainly 3 important messages are as follows:

I) Calibrate the property of layers in vertical direction and point out there are 3 three interfaces in the vertical direction which are Yanshan small granite-porphyry rock low-density layer, Caledonian Dragon King rock low- 
density layer, Xiong'er xushan group and Taihua group high-density layers with bouguer gravity anomaly.

II) G5 heishijia hidden rocks reflecting low density anomaly,G6 muzhuao low density anomaly hidden rocks and G9 luocun low density anomaly hidden rocks between Caledonian Iron rich ekerite and the location of north Taihua group are most related anomalies to molybdenum mineralization.

III) TA-2 IP anomaly follows a similar pattern which caused by luocun rock body and metamorphic rocks in contact zone, so the location of TA-2 anomaly is a mineralization favourable position which we should pay highly attention to it.

\section{REFERENCES}

[1] Li Xing, Dou Yueer, Metallognic characteristics and Prospecting of Daqinggou Molybdenum Deposit in Luanchuan County, Henan. ProvinceResources Environment \&Engineering 22(3), 310-315, 2008.

[2] Yang Changlong, Liu Zhanchen, The Relation of Luocun Porphyry Body Characteristics and Mineralization in Luanchuan, Henan Province. Mineral Resources and Geology 24(4), 328-332, 2010.

[3] Guo Jianwei, He Shuqin, Bai Fengjun, Geological characteristics of Luocun molybdenum mine in Luanchuan, Henan and its prospecting priority. Mineral Resources and Geology, 21(3), 321-352, 2007.

[4] Bai Fengjun, Metallogenic geological characteristics and prospecting orientation of Luocun porphyry-breccias molybdenum deposit. Mineral Resources and Geology, 21(5), 527-531, 2007. 